Pak. j. sci. ind. res. Ser. A: phys. sci. 2019 62A(3) 174-180

\title{
Pretreatment of Cotton with Different Radiations to Improve Colour Strength and Fastness Properties in Reactive Dyeing
}

\author{
Assad Farooq ${ }^{\mathrm{a}}$, Amna Amjad ${ }^{\mathrm{b}, \mathrm{c}}$, Muhammad Azeem Ashraf ${ }^{\text {a* }}$ and Jawairia Umar Khan ${ }^{\mathrm{a}}$ \\ ${ }^{a}$ Department of Fibre and Textile Technology, University of Agriculture, Faisalabad, Pakistan \\ ${ }^{\mathrm{b}}$ Institute of Home Sciences, University of Agriculture, Faisalabad, Pakistan \\ ${ }^{\mathrm{c}}$ Department of Design, National Textile University, Faisalabad, Pakistan
}

(received February 12, 2018; revised February 20, 2019; accepted February 22, 2019)

\begin{abstract}
Different types of radiations have been found to be widely applicable in modifying the properties of materials. In this work colour strength $(\mathrm{K} / \mathrm{S})$ and colour fastness of reactive dyed cotton fabric has been studied with the application of three radiations; microwave, ultraviolet and ultrasonic. Analysis of variance and comparison of mean values statistical tests were carried out to find out the effect of different radiation treatment time and fabric density on colour strength of cotton fabrics. The colour strength $(\mathrm{K} / \mathrm{S})$ of dyed fabric enhanced significantly by pretreatment with different radiations and highest shade depth is achieved in case of microwave in comparison to untreated ultrasonic and ultraviolet irradiated samples. Furthermore, irradiated samples have shown better colour fastness to washing in all three cases. Therefore these radiations can be used to enhance the colour properties of dyed fabrics.
\end{abstract}

Keywords: microwave irradiation, ultraviolet irradiation, ultrasonic irradiation, cotton fabric, colour srength

\section{Introduction}

Radiation can be defined as a form of energy in a more precise way that is present everywhere and can be of varied forms like radio waves, microwave, X-rays, gamma, ultraviolet and a lot more. The energy from sun is a form of electromagnetic energy. In the sense of classical theory, radiation generates the energy flow at the universal speed of light either via free space or in the form of electric and magnetic fields that collectively generate various waves such as radio waves, gamma, microwave, infrared and ultraviolet (Lucas, 2015).

Manmade radiations have a great influence in our daily life. We use microwave ovens for food heating, broadcasting stations transmit radiations which are received by our television sets. Ultraviolet radiations are used to sterilize medical instruments and effectively kill bacteria and viruses. UV radiations also lighten up the incandescent materials. Gamma radiations are used to treat a variety of cancer and cancer causing cells etc. (Fritzsche and Phillips, 2017).

There are several commercially important applications of these irradiation processes; in printing, metal coating, wood finishing, plastics and glass, electrical insulations.

*Author for correspondence;

E-mail: azeemashraf786@hotmail.com
This technology has broader well known advantages like energy reduction, less environmental impact, costeffective and high process speed. Regardless of these advantages, textile industry also have notable applications of radiation curing, such as non-woven fabric bonding and pigment printing (Ferrero and Periolatto, 2011).

Cotton is the widely available cellulose fibre (Mohsin et al., 2013). Cotton has excellent dye uptake due to bonding of various dyes with hydroxyl groups of cellulosic structure (Wojnárovits et al., 2010). Fabric and garments coloration through radiation treatment can append significant worth. Also, there are possibilities of fibre surface modification that can permit more dye uptake, in addition to enhance wettability of fabric and its fixation at low temperature. Effect of UV radiations and others in natural and synthetic dyeing has shown substantial results (Kim et al., 2006).

Over the years, many techniques have been used to enhance the dyeing and colourfastness of textile materials. Such techniques include enzyme treatment (Kan et al., 2011), cationization (Haddar et al., 2014), ultrasonic (Farooq et al., 2018; 2013), UV treatment (Adeel et al., 2014), gamma treatment (Adeel et al., 2015). These techniques modify the surface of textiles and enhance the fastness properties. Their increasing 
use is because of their energy efficiency, cost effectiveness, lower time and environment friendly nature (Usman et al., 2016; Ferrero and Periolatto, 2011). The major benefit of these irradiation processes is the low energy use which is bliss in this era of high energy crisis and obviously high speed process. These radiation treatments activate textile surfaces and hence giving tremendous results after finishing and dyeing (Shahid-ul-Islam and Mohammad, 2015).

In this work physical and mechanical characteristics of reactive dyed cotton fabric have been studied with the application of three radiations; microwave, ultraviolet and ultrasonic. The work was aimed to enhance the colour strength as well as to improve colour fastness properties by using different radiations.

\section{Materials and Methods}

$100 \%$ scoured and bleached cotton fabric samples having characteristics as given in Table 1 were used for this work.

The research work was carried out in three steps (1) pretreatment of cotton fabrics with different radiations; (2) dyeing of fabrics with reactive dyes in three shades and (3) performance evaluation of treated fabrics.

Irradiation of fabric with different radiations. Pretreatment with microwave irradiation. A Panasonic microwave oven model no. NN-CD997S/NN-CD987W having frequency $2450 \mathrm{MHz}$ was used for irradiation. The cotton samples were irradiated at 1000 watt in water with liquor ratio $1: 14$ for 10 and $15 \mathrm{~min}$.

Pretreatment with ultrasonic irradiation. AED X-3 ultrasonic bath of $40 \mathrm{kHz}$ frequency was used for the irradiation of samples. The samples were soaked in water bath at $80^{\circ} \mathrm{C}$. The samples were irradiated for 30 and $60 \mathrm{~min}$, respectively.

Pretreatment with ultraviolet irradiation. Fabric samples were irradiated with UV light for 30 and $60 \mathrm{~min}$.

Dyeing of fabrics with reactive dye. Samples were dyed with reactive dye in three different shades using

Table 1. Fabric characteristics

\begin{tabular}{lll}
\hline \hline Density & GSM & Tensile strength $(\mathrm{N})$ \\
\hline $76 \times 66$ & 121.6 & 424.27 \\
$76 \times 54$ & 103.4 & 414.37 \\
$76 \times 42$ & 93.2 & 380.54 \\
\hline \hline
\end{tabular}

IR dyeing machine (Advance System Logic) at 1:15 liquor ratio, for $60 \mathrm{~min}$ at $60{ }^{\circ} \mathrm{C}$ according to the following recipes given in Table 2 . After dyeing samples were washed with water and treated with solution having acid $1.3 \mathrm{~g} / \mathrm{L}$ and Cotoblanc $0.7 \mathrm{~g} / \mathrm{L}$.

Table 2. Dyeing recipes

\begin{tabular}{llll}
\hline \hline Chemicals & Light & Medium & Dark \\
\hline Remazol Yellow 3RS & $0.5 \%$ & $1.5 \%$ & $2.5 \%$ \\
Soda ash & $10 \mathrm{~g} / \mathrm{L}$ & $10 \mathrm{~g} / \mathrm{L}$ & $20 \mathrm{~g} / \mathrm{L}$ \\
Common salt & $25 \mathrm{~g} / \mathrm{L}$ & $40 \mathrm{~g} / \mathrm{L}$ & $65 \mathrm{~g} / \mathrm{L}$ \\
\hline \hline
\end{tabular}

Testing of fabric characteristics. The physical and mechanical testing was carried out for the quality assurance and to determine the characteristics of the dyed fabrics. Colour strength $(\mathrm{K} / \mathrm{S})$ was measured on spectrophotometer (Data colour SF-600), tensile strength ISO-13934-1 was measured on Spartan (Advance System Logic) and colour fastness to washing ISO105-C03 was carried out on Launder-o-meter (SDL Atlas, USA).

\section{Results and Discussion}

Colour strength $(\mathrm{K} / \mathrm{S})$. Colour strength $(\mathrm{K} / \mathrm{S})$ with microwave pretreatment. The colour strength $(\mathrm{K} / \mathrm{S})$ of dyed cotton fabrics pretreated with microwave in comparison to untreated fabrics is presented in Fig. 1.

The samples showed improved colour strength after irradiating with microwave in comparison to untreated dyed samples. Microwave irradiation treatment produces dense colour, with higher colour fastness. These

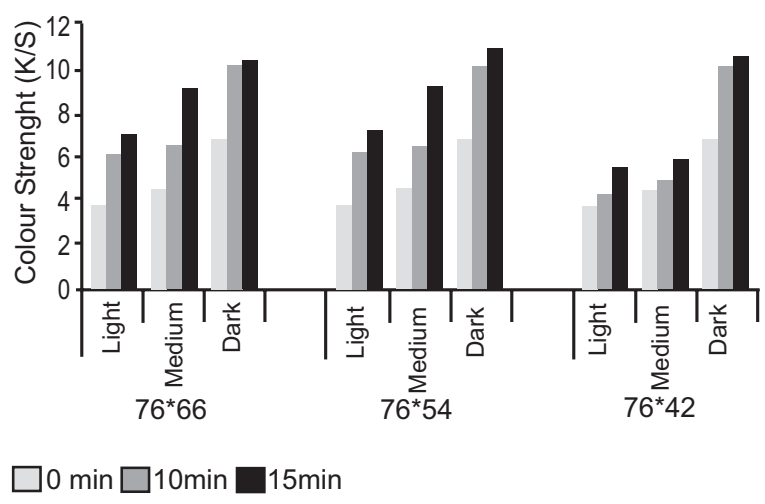

Fig. 1. Colour strength of dyed cotton fabrics pretreated with microwave. 
radiations produce micro cracks on the surface of fibres which increase the dye uptake and results in higher colour strength (Al-Mousawi et al., 2013). It indicates that the microwave assisted dyeing can provide better results by consuming less energy and less time (Irfan et al., 2018). Results showed that microwave irradiation could be successfully used in reactive dye fixation and the $\mathrm{K} / \mathrm{S}$ value depends on time of exposure to microwave hence improving shade depth.

Materials absorb energy internally and directly in case of microwave treatment which results in uniform and rapid heating. In dielectric materials, microwave heating converts wave form energy into thermal form. Materials like water having high dielectric constant can be selfheated by the rotation of dipole during microwave radiation process (Kappe and Dallinger, 2009).

The analysis of variance (ANOVA) for colour strength presented in Table 3 shows that the effect of microwave and shade is highly significant while the effect of fabric type is nonsignificant.

The individual comparison of mean values for colour strength given in Table 4, shows no significant pairwise differences among the mean values for different fabric densities however, in case of radiation time i.e., microwave, the individual comparison of mean values shows that there are significant differences between values. The results are in accordance with the studies of De-Chao (2015) who reported that microwave treatment has significant effect on colour.

Colour strength $(K / S)$ with ultrasonic pretreatment. The colour strength of dyed cotton fabrics pretreated

Table 3: Analysis of variance for colour strength of microwave treated fabrics

\begin{tabular}{llllll}
\hline \hline Source & DF & SS & MS & F & P \\
\hline Fabric & 2 & 5.319 & 2.6597 & 9.4 & $0.0589 \mathrm{NS}$ \\
Microwave & 2 & 52.331 & 26.1657 & 92.45 & $0.0000^{* *}$ \\
Shade & 2 & 74.971 & 37.4855 & 132.44 & $0.0000^{* *}$ \\
Fabric* & 4 & 2.956 & 0.739 & 2.61 & $0.1156 \mathrm{NS}$ \\
$\begin{array}{l}\text { Microwave } \\
\text { Fabric* }\end{array}$ & 4 & 2.939 & 0.7348 & 2.6 & $0.1169 \mathrm{NS}$ \\
Shade & & & & & \\
$\begin{array}{l}\text { Microwave* } \\
\text { Shade }\end{array}$ & 4 & 4.117 & 1.0293 & 3.64 & $0.0568 \mathrm{NS}$ \\
Error & 8 & 2.264 & 0.283 & & \\
Total & 26 & 144.899 & & & \\
\hline \hline
\end{tabular}

$* *=$ Highly significant; $*=$ Significant; NS=Non Significant
Table 4. Comparison of treatment means for colour strength of microwave treated fabrics

\begin{tabular}{lll}
\hline \hline Fabric Density & Microwave time & Shade \\
\hline $\mathrm{D}_{1}=6.95 \mathrm{a}$ & $\mathrm{T}_{1}=5.01 \mathrm{c}$ & $\mathrm{S}_{1}=5.15 \mathrm{c}$ \\
$\mathrm{D}_{2}=7.20 \mathrm{a}$ & $\mathrm{T}_{2}=7.16 \mathrm{~b}$ & $\mathrm{~S}_{2}=6.13 \mathrm{~b}$ \\
$\mathrm{D}_{3}=7.12 \mathrm{a}$ & $\mathrm{T}_{3}=8.37 \mathrm{a}$ & $\mathrm{S}_{3}=9.15 \mathrm{a}$ \\
\hline
\end{tabular}

(Mean values having different letters differ significantly at $0.05 \%$ level of probability)

with ultrasonic radiations in comparison to untreated fabrics is presented in Fig. 2. Shade depth of fabrics irradiated with ultrasonic samples showed improved colour strength in comparison to untreated dyed samples. Ultrasonic radiations open the micro pores in the fibre structure and enhance the dye penetration which increased linkage of dye molecules with cotton.

Ultrasonic radiations improved the dyeing rate by rapid diffusion which gives higher colour strength (Tissera et al., 2015). Ultrasonic treatment is a potential technique which reduces the time, energy and cost (Guesmi et al., 2013).

The analysis of variance (ANOVA) for colour strength presented in Table 5 shows that the effect of fabric type is nonsignificant while the effect of microwave and shade is highly significant. The individual comparison of mean values given in Table 6 , shows no significant pairwise differences among the mean values for different fabric densities. In case of radiation time i.e., ultrasonic, the individual comparison of mean values shows nonsignificant differences between values.

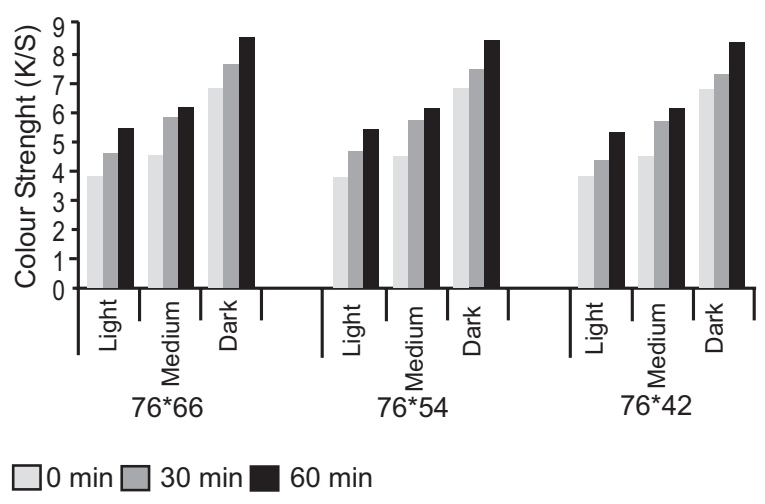

Fig. 2. Colour strength of dyed cotton fabrics pretreated with ultrasonic. 
Table 5. Analysis of variance for colour strength of ultrasonic treated fabrics

\begin{tabular}{llllll}
\hline \hline Source & DF & SS & MS & F & P \\
\hline Fabric & 2 & 0.0664 & 0.0332 & 16.16 & $0.0516 \mathrm{NS}$ \\
Ultrasonic & 2 & 11.9247 & 5.9623 & 2900.6 & $0.0000^{* *}$ \\
$\begin{array}{l}\text { Shade } \\
\text { Fabric* }\end{array}$ & 2 & 43.1233 & 21.5616 & 10489.4 & $0.0000^{* *}$ \\
$\begin{array}{l}\text { Ultrasonic } \\
\text { Fabric* }\end{array}$ & 4 & 0.042 & 0.0105 & 5.11 & $0.0242^{*}$ \\
$\begin{array}{l}\text { Shade } \\
\text { Ultrasonic* }\end{array}$ & 4 & 0.0136 & 0.0034 & 1.65 & $0.2528 \mathrm{NS}$ \\
$\begin{array}{l}\text { Shade } \\
\text { Error }\end{array}$ & 4 & 0.3754 & 0.0939 & 45.66 & $0.0002^{* *}$ \\
Total & 8 & 0.0164 & 0.0021 & & \\
\hline \hline
\end{tabular}

**=Highly significant; $*=$ Significant; $\mathrm{NS}=$ Non Significant

Table 6. Comparison of treatment means of colour strength for ultrasonic treated fabrics

\begin{tabular}{lll}
\hline \hline Fabric density & Ultrasonic time & Shade \\
\hline $\mathrm{D}_{1}=5.78 \mathrm{a}$ & $\mathrm{T}_{1}=5.01 \mathrm{c}$ & $\mathrm{S}_{1}=4.54 \mathrm{c}$ \\
$\mathrm{D}_{2}=5.85 \mathrm{a}$ & $\mathrm{T}_{2}=5.89 \mathrm{~b}$ & $\mathrm{~S}_{2}=5.44 \mathrm{~b}$ \\
$\mathrm{D}_{3}=5.90 \mathrm{a}$ & $\mathrm{T}_{3}=6.63 \mathrm{a}$ & $\mathrm{S}_{3}=7.55 \mathrm{a}$ \\
\hline \hline
\end{tabular}

(Mean values having different letters; differ significantly at $0.05 \%$ level of probability)

Colour strength $(\mathrm{K} / \mathrm{S})$ with ultraviolet pretreatment. The colour strength of dyed cotton fabrics pretreated with ultraviolet radiations in comparison to untreated fabrics is presented in Fig. 3. The ultraviolet irradiated samples showed higher colour strength in comparison to untreated dyed samples.

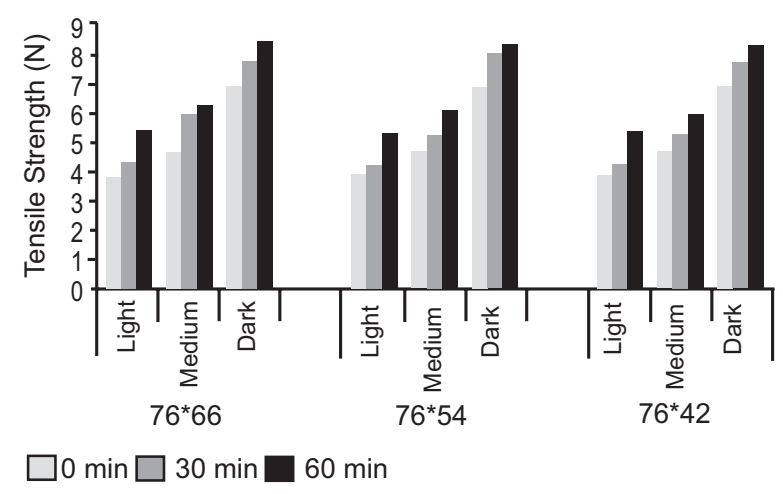

Fig. 3. Colour strength of dyed cotton fabrics pretreated with ultraviolet.
Results showed higher colour strength by increasing time interval of irradiation. This might be due to the fact that ultraviolet irradiation of cellulosic fabric causes oxidation of cellulose forming carboxylic groups with spaces between fibres hence improving dye interaction to fibre. So better dye uptake means better fastness properties.

The analysis of variance (ANOVA) for colour strength presented in Table 7 shows that the effect of fabric type is nonsignificant while the effect of microwave and shade is highly significant. The individual comparison of mean values given in Table 8 , shows no significant pairwise differences among the mean values for different fabric densities. In case of radiation time i.e., ultraviolet and shade the individual comparison of mean values shows significant differences between values.

Tensile strength. Tensile strength with microwave pretreatment. The tensile strength of dyed cotton fabrics pretreated with microwave radiations in comparison to untreated fabrics is presented in Fig. 4.

The results showed that tensile strength is decreased slightly by application of microwave treatment. The

Table 7. Analysis of variance for colour strength of ultraviolet treated fabrics

\begin{tabular}{llllll}
\hline \hline Source & DF & SS & MS & F & P \\
\hline Fabric & 2 & 0.0924 & 0.0462 & 2.58 & $0.1362 \mathrm{NS}$ \\
Ultraviolet & 2 & 9.2737 & 4.6369 & 259.39 & $0.0000^{* *}$ \\
Shade & 2 & 47.9266 & 23.9633 & 1340.53 & $0.0000^{* *}$ \\
$\begin{array}{l}\text { Fabric* } \\
\text { Ultraviolet }\end{array}$ & 4 & 0.0733 & 0.0183 & 1.03 & $0.4500 \mathrm{NS}$ \\
$\begin{array}{l}\text { Fabric* } \\
\text { Shade }\end{array}$ & 4 & 0.1203 & 0.0301 & 1.68 & $0.2461 \mathrm{NS}$ \\
$\begin{array}{l}\text { Ultraviolet * } \\
\text { Shade }\end{array}$ & 4 & 0.3267 & 0.0817 & 4.57 & $0.0325^{*}$ \\
$\begin{array}{l}\text { Error } \\
\text { Total }\end{array}$ & 8 & 0.143 & 0.0179 & & \\
\hline **=Highly & significant; & $*=$ Significant; & $\mathrm{NS}=$ Non \\
Significant & & & & & \\
\hline
\end{tabular}

Table 8. Comparison of treatment means of colour strength for ultraviolet treated fabrics

\begin{tabular}{lll}
\hline \hline Fabric Density & Ultraviolet Time & Shade \\
\hline $\mathrm{D}_{1}=5.68 \mathrm{a}$ & $\mathrm{T}_{1}=5.02 \mathrm{c}$ & $\mathrm{S}_{1}=4.38 \mathrm{c}$ \\
$\mathrm{D}_{2}=5.72 \mathrm{a}$ & $\mathrm{T}_{2}=5.74 \mathrm{~b}$ & $\mathrm{~S}_{2}=5.29 \mathrm{~b}$ \\
$\mathrm{D}_{3}=5.82 \mathrm{a}$ & $\mathrm{T}_{3}=6.46 \mathrm{a}$ & $\mathrm{S}_{3}=7.55 \mathrm{a}$ \\
\hline
\end{tabular}

(Mean values having different letters differ significantly at $0.05 \%$ level of probability) 


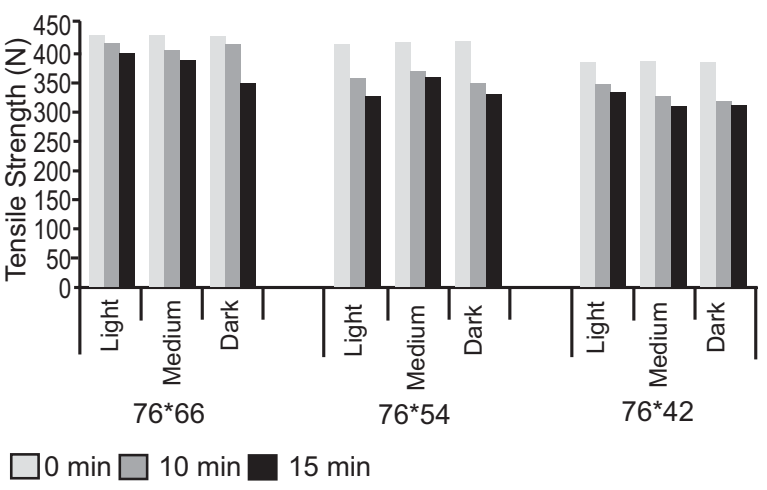

Fig. 4. Tensile strength of dyed cotton fabrics treated with microwave.

decreased tensile strength may occur due to the fact that longer radiations time makes the fibers weak, so it has significant effect on tensile properties. The results are supported by Xue and Jin-Xin (2011) studies, who stated that fibres find difficulty in maintaining fine structure and obtain more heat under microwave irradiation which can results in decreasing strength.

Tensile strength with ultrasonic pretreatment. The tensile strength of dyed cotton fabrics pretreated with ultrasonic radiations is presented in Fig. 5.

The results show that tensile strength is higher at 0 minutes while decreasing trend can be observed by increasing treatment time. Ultrasonic treatment of 30 min showed the better tensile strength which means when fabric is exposed to shorter time duration there is minimum strength loss. The reason of higher strength for $30 \mathrm{~min}$ and decreasing behavior for $60 \mathrm{~min}$ is that

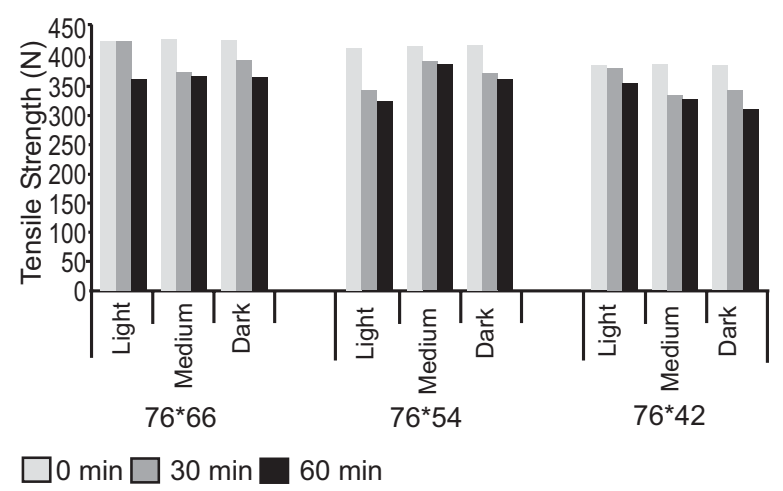

Fig. 5. Tensile strength of cotton fabrics treated with ultrasonic longer irradiation time might make the fibres weak (Arora et al., 2012).

Tensile strength with ultraviolet pretreatment. The results for tensile strength of dyed fabrics pretreated with ultraviolet presented in Fig. 6 shows a decreasing trend after ultraviolet treatment. The ultraviolet treatment of $30 \mathrm{~min}$ have shown the better tensile strengths as compared to $60 \mathrm{~min}$ which might be due to the fact that longer irradiation time may have made the fibres weak. The decreased strength properties may be due to the fact that ultraviolet rays can break down the chemical bonds hence affecting strength. Ultraviolet irradiated samples however showed overall better strength in comparison to microwave and ultrasonic.

Colour fastness to washing. The untreated and irradiated reactively dyed cotton fabrics with all three shades were subjected to washing for $30 \mathrm{~min}$ at $60^{\circ} \mathrm{C}$ to observe the effects. Each sample was washed and compared with the grey scale. The grey scale rating of dyed cotton fabrics pretreated with different radiations in comparison to untreated fabrics is presented in Table 9.

The grey scale ratings of microwave irradiated fabrics were mostly excellent (5) for light and medium shades while very good to excellent (4-5) in case of dark shade. The good fastness properties may be due to better intrafibre diffusion of dye molecules within the fabrics. The results are according to the findings of Haggag et al. (2014) who reported that colour properties are found to be good to excellent in case of microwave irradiation due to even and continuous heating system. Thus microwave treatment can be successfully used to improve the colour fastness properties. Microwave

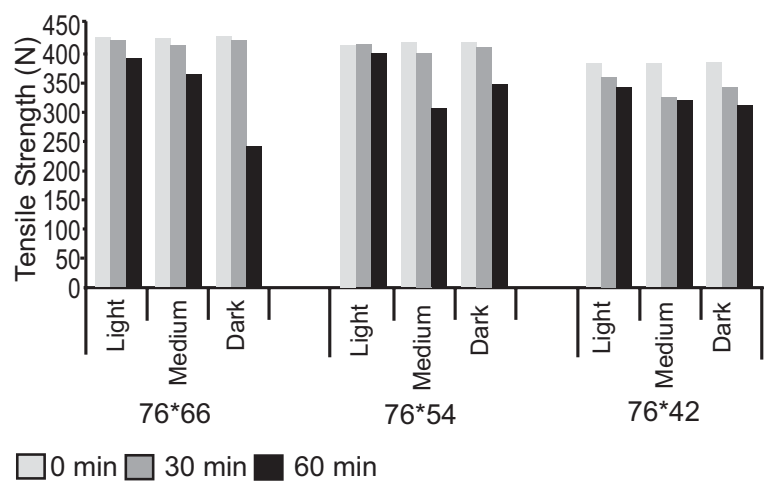

Fig. 6. Tensile strength of cotton fabrics treated with ultraviolet irradiation 
Table 9. Colour fastness to washing of dyed fabrics pre-treated with different radiations

\begin{tabular}{|c|c|c|c|c|c|c|c|c|c|c|}
\hline \multirow[t]{3}{*}{ Shade } & \multirow{3}{*}{$\begin{array}{l}\text { Treatment } \\
\text { time (min) }\end{array}$} & \multicolumn{6}{|c|}{ Washing fastness } & & & \\
\hline & & \multicolumn{3}{|c|}{ Microwave } & \multicolumn{3}{|c|}{ Ultrasonic } & \multicolumn{3}{|c|}{ Ultraviolet } \\
\hline & & $76 \times 66$ & $76 \times 54$ & $76 \times 42$ & $76 \times 66$ & $76 \times 54$ & $76 \times 42$ & $76 \times 66$ & $76 \times 54$ & $76 \times 42$ \\
\hline \multirow[t]{3}{*}{ Light } & 0 & 4 & 4 & 4 & 4 & 4 & 4 & 4 & 4 & 4 \\
\hline & 10 & 5 & 5 & 5 & $4-5$ & $4-5$ & $4-5$ & $4-5$ & $4-5$ & $4-5$ \\
\hline & 15 & 5 & 5 & 5 & 5 & 5 & 5 & $4-5$ & $4-5$ & $4-5$ \\
\hline \multirow[t]{3}{*}{ Medium } & 0 & 4 & 4 & 4 & 4 & 4 & 4 & 4 & 4 & 4 \\
\hline & 10 & $4-5$ & $4-5$ & $4-5$ & $4-5$ & $4-5$ & $4-5$ & $4-5$ & $4-5$ & $4-5$ \\
\hline & 15 & 5 & 5 & 5 & $4-5$ & $4-5$ & $4-5$ & $4-5$ & $4-5$ & $4-5$ \\
\hline \multirow[t]{3}{*}{ Dark } & 0 & $3-4$ & $3-4$ & $3-4$ & $3-4$ & $3-4$ & $3-4$ & $3-4$ & $3-4$ & $3-4$ \\
\hline & 10 & $4-5$ & $4-5$ & $4-5$ & 4 & 4 & 4 & 4 & 4 & 4 \\
\hline & 15 & $4-5$ & $4-5$ & $4-5$ & 4 & 4 & 4 & 4 & 4 & 4 \\
\hline
\end{tabular}

radiation is an eco-friendly source of heating which can be successfully used in textile wet processing specially in dyeing and finishing. Under the microwave irradiation dye colour yield increased due to constant and even heating which results in better colour fastness properties (Adeel et al., 2018).

In case of ultrasonic irradiated samples, dyed fabrics showed mostly very good to excellent (4-5) rating for light and medium shades while very good (4) for dark shade. Ultrasonic treatment improved colour strength of dyed fabrics due to better uptake of dyes (Farooq et al., 2018).

In case of dyed fabrics pretreated with ultraviolet radiations grey scale rating for washing fastness was very good to excellent (4-5) for light and medium shades while very good (4) for dark shade. Dyed fabrics pretreated with microwave radiations showed better washing fastness results as compared to ultrasonic and ultraviolet irradiated fabrics. Micheal and El-Zaher (2005) reported that when cellulosic fibres like cotton are irradiated with ultraviolet or other technologies, spaces are produced between fibres and as a result more dye can be absorbed which produces significant results of fastness properties.

\section{Conclusion}

Different radiations were used to investigate their effect on colour strength $(\mathrm{K} / \mathrm{S})$, tensile strength and colour fastness of cotton fabrics dyeing with reactive dyes. Analysis of variance (ANOVA) test shows the statistical significant effect of radiations pretreatment on colour strength $(\mathrm{K} / \mathrm{S})$ and tensile strength of reactive dyed cotton fabrics. The colour strength $(\mathrm{K} / \mathrm{S})$ of dyed fabric enhanced significantly by pretreatment with different radiations and highest shade depth is achieved in case of microwave in comparison to ultrasonic and ultraviolet irradiated samples. Therefore, these radiations can be used to enhance the colour strength and fastness properties of dyed fabrics.

Conflict of Interest. The authors declare no conflict of interest

\section{References}

Adeel, S., Khan, S. G., Shahid, S., Saeed, M., Kiran, S., Zuber, M., Suleman, M., Akhtar, N. 2018. Sustainable dyeing of microwave treated polyester fabric using disperse yellow 211 dye. Journal of the Mexican Chemical Society, 62: 1-10.

Adeel, S., Usman, M., Haider, W., Saeed, M., Muneer, M., Ali, M. 2015. Dyeing of gamma irradiated cotton using direct yellow 12 and direct yellow 27: Improvement in colour strength and fastness properties. Cellulose, 22: 2095-2105.

Adeel, S., Hanif, R., Zuber, M., Muneer, M. 2014. Ecofriendly dyeing of uv-irradiated cotton using extracts of Acacia nilotica bark (kikar) as source of quercetin. Asian Journal of Chemistry, 26: 830834.

Al-Mousawi, S. M., El-Apasery, M. A., Mahmoud, H. M. 2013. Disperse dyes based on aminothiophenes: Their dyeing applications on polyester fabrics and their antimicrobial activity. Molecules, 18: 70817092.

Arora, A., Rastogi, D., Gupta, D., Gulrajani, M., 2012. Dyeing parameters of hydroxynaphthoquinones extracted from Arnebia nobilis Rech. F. Indian Journal of Fibre and Textile Research, 37: 91-97.

De-Chao, H. 2015. The application advantages of 
microwave fixation in cotton fabric dyeing. In: International Conference on Education Technology, Management and Humanities Science.

Farooq, A., Ashraf, M.A., Rasheed, A., Khan, J.U., Irshad, F. 2018. Development of a novel method for natural dyeing of cotton fabrics using ultrasonic radiations and Acacia bark. Journal of Natural Fibers, 15: 680-686.

Farooq, A., Ashraf, M. A., Mohsin, M. 2013. Effect of conventional and ultrasonic assisted bleaching on colour fastness properties of reactive dyed cotton fabric. Asian Journal of Chemistry, 25: 5960-5964.

Ferrero, F., Periolatto, M. 2011. Ultraviolet curing for surface modification of textile fabrics. Journal of Nanoscience and Nanotechnology, 11: 8663-8669.

Fritzsche, H., Phillips, M. 2017. The electromagnetic spectrum. In: Encyclopædia Britannica: Encyclopædia Britannica, inc.

Guesmi, A., Ladhari, N., Sakli, F. 2013. Ultrasonic preparation of cationic cotton and its application in ultrasonic natural dyeing. Ultrasonics Sonochemistry, 20: 571-579.

Haddar, W., Ticha, M. B., Guesmi, A., Khoffi, F., Durand, B. 2014. A novel approach for a natural dyeing process of cotton fabric with Hibiscus mutabilis (gulzuba): Process development and optimization using statistical analysis. Journal of Cleaner Production, 68: 114-120.

Haggag, K., El-Mollaa, M., Mahmoued, Z. 2014. Dyeing of cotton fabrics using reactive dyes by microwave irradiation technique. Indian Journal of Fibre \& Textile Research, 39: 406-410.

Irfan, M., Zhang, H., Syed, U., Hou, A. 2018. Low liquor dyeing of cotton fabric with reactive dye by an eco-friendly technique. Journal of Cleaner Production, 197: 1480-1487.

Kan, C., Yuen, C., Wong, W. 2011. Optimizing color fading effect of cotton denim fabric by enzyme treatment. Journal of Applied Polymer Science, 120: 3596-3603.

Kappe, C.O., Dallinger, D. 2009. Controlled microwave heating in modern organic synthesis: Highlights from the 2004-2008 literature. Molecular Diversity, 13: 71 .

Kim, J.K., Jo C., Hwang, H.J., Park, H.J., Kim, Y.J., Byun, M.W. 2006. Color improvement by irradiation of Curcuma aromatica extract for industrial application. Radiation Physics and Chemistry, 75: 449-452.

Lucas, J. 2015 What is electromagnetic radiation [cited 17 Jan. 2017. Available from https://www. livescience.com/38169-electromagnetism.html.

Micheal, M., El-Zaher, N. 2005. Investigation into the effect of uv/ozone treatments on the dyeing properties of natural dyes on natural fabrics. Colourage, 52: 83-88.

Mohsin, M., Rasheed, A., Farooq, A., Ashraf, M., Shah, A. 2013. Environment friendly finishing of sulphur, vat, direct and reactive dyed cotton fabric. Journal of Cleaner Production, 53: 341-347.

Shahid-ul-Islam, M.F. 2015. High-energy radiation induced sustainable coloration and functional finishing of textile materials. Industrial \& Engineering Chemistry Research, 54: 3727-3745.

Tissera, N.D., Wijesena, R.N., de Silva, K.N. 2015. Ultrasound energy to accelerate dye uptake and dye-fiber interaction of reactive dye on knitted cotton fabric at low temperatures. Ultrasonics Sonochemistry, 29: 270-278.

Usman, M., Adeel, S., Haider, W., Ghaffar, A., Rehman, F., Ali, M. 2016. Dyeing of biotreated and gamma irradiated cotton fabric using direct yellow 12 and direct yellow 27. Journal of Natural Fibers, 13: 483-491.

Wojnárovits, L., Földváry, C. M., Takács, E. 2010. Radiation-induced grafting of cellulose for adsorption of hazardous water pollutants: A review. Radiation Physics and Chemistry, 79: 848-862.

Xue, Z., Jin-Xin, H. 2011. Effect of microwave irradiation on the physical properties and structures of wool fabric. Journal of Applied Polymer Science, 119: 944-952. 